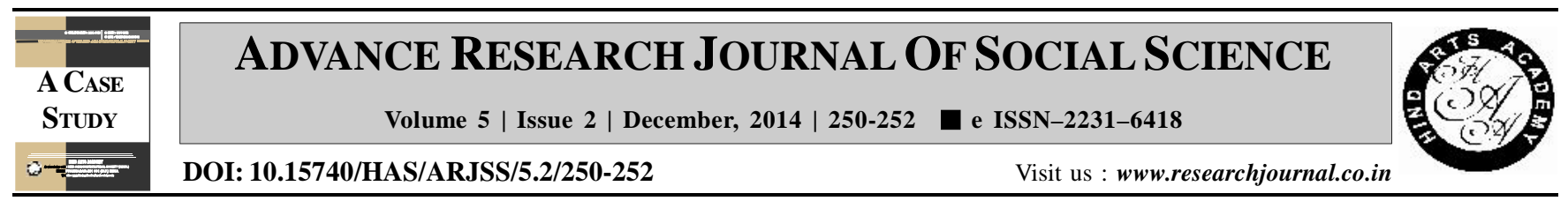

\title{
Perception of retired women about life in general
}

Pritishri Parhi* and Manashi Mohanty ${ }^{1}$

Department of Human Development and Family Studies, College of Home Science, Orissa University of Agriculture and Technology, BHUBANESWAR (ORISSA) INDIA

${ }^{1}$ Department of Family Resource Management, College of Home Science, Orissa University of Agriculture and Technology, BHUBANESWAR (ORISSA) INDIA

\section{ARTICLE INFO :}

Received

: 27.10 .2014

Accepted

27.11 .2014

KEY WORDS :

Perception, Leisure time, General life

HOW TO CITE THIS ARTICLE :

Parhi, Pritishri and Mohanty, Manashi (2014).

Perception of retired women about life in general.

Adv. Res. J. Soc. Sci., 5 (2) : 250-252.

*Author for correspondence

\begin{abstract}
Most of the working women spend their time in such a hectic way that they don't plan and prepare themselves for their retirement life and suddenly retirement come to them. They then feel the life is totally different and their perception towards their daily work, their family and life has changed. In this context, the present study was undertaken which revealed medium level of perception about life in general, greater clarity of concept with maturity and making of leisure time more interesting and remunerative by the retired women.
\end{abstract}

